\title{
The Pack Hunter (Dhole): Received Little Scientific Attention
}

\author{
Mr. Ambika Pd. Khatiwada ${ }^{1}$, Dr. K. D. Awasthi ${ }^{1}$, Mr. Narayan Pd. Gautam ${ }^{1}$ \\ Dr. Shant Raj Jnawali ${ }^{2}$, Mr. Naresh Subedi², Mr. Achyut Aryal ${ }^{3}$ \\ Corresponding author : Ambika Khatiwada \\ Email : ambikakhatiwada@yahoo.com
}

\begin{abstract}
:
The dholes received little scientific attention due to the lower charisma factor than other larger carnivores found in the same areas like Tiger and Snow Leopard. This is the first study of dholes that was conducted in Kanchenjunga Conservation Area (KCA), Nepal in 2010. Camera trapping, sign survey, interview and group discussion with local people were carried out to assess the presencelabsence of dholes in $K C A$, conflict with humans and to know the history of dholes in the area. The camera trapping evidence (Three pictures of dholes caught on camera trap) confirmed the dhole presence in KCA. According to the Snow Leopard Conservation Sub-Committee (SLCC) report about 87.5\% of livestock were killed by dholes only in Yamphudin. Conservation education and comprehensive carnivore conservation action plan is recommended for the conservation of dholes.
\end{abstract}

Key Words: Asiatic Wild Dog, Human-Dhole Conflict, SLCC, Camera Trapping

\section{Introduction:}

The dholes or Asiatic wild dogs (Cuon alpinus) are one of the least studied social carnivores in the world. Dhole range includes central and east Asia, from China (Manchuria) in the north to India and the Malay Peninsula in the South. They are also found on the islands of Sumatra and Java but are absent in Borneo, Srilanka and Japan (Johnsingh 1985). Despite this wide distribution, dholes occur at low densities that warrant international protection. The dhole is listed as an appendix II species by the Convention on International Trade in Endangered Species of Wild Fauna and Flora (CITES 2010) and endangered by the IUCN Red List of Threatened Species with the decreasing population trend (IUCN 2010). These dogs are distributed from tropical forests to the high mountains of Nepal's protected areas. These dogs received little conservation efforts due to lower charisma factor than other large carnivores of the same area (eg. Tiger, Snow Leopard).

\footnotetext{
${ }^{1}$ Institute of Forestry, Pokhara, Nepal

${ }^{2}$ National Trust for Nature Conservation (NTNC), Nepal

${ }^{3}$ Biodiversity Research and Training Forum (BRTF), Nepal
} 
Dholes were camera trapped in KCA during this study in August, 2010. Inhabiting a wide range of climates, from cold mountains to tropical valleys, dholes are grouped with wolves, coyotes, and foxes in the taxonomic classification of canidea. Like most dog species, they are very good at adapting to a range of habitat. In Kangchenjunga Conservation Area (KCA), dholes travel on trails frequented by humans and domestic animals and prefer to follow the ridge of the mountains. The dhole population has been estimated to be fewer than 2,500 in the wild. Past research has focused primarily on dholes in southern and central India and Thailand. This is the first study of dholes conducted in the KCA in Nepal.

The term 'dhole' is reported to have an ancient Asiatic origin signifying "recklessness and daring" (Wikipedia 2011). Dholes are of reddish color with beautiful plume like black tail. The local people of KCA call them "Ban Kukur" meaning forest dog. Their ears are always erect reflecting the activeness and this is reflected in the locals calling them "Thada Kane" and being fast moving animals these dogs are also called as "Milke" at the villages.

The prime factors that determine dhole habitats are prey abundance, water availability, interspersion of forests with grassy openings, minimum human disturbance, and potential den sites (Johnsingh 1985). Dholes are highly social animals with a rigid structure of fixed dominance hierarchies (Iyengar et al. 2005). They also exhibit a high level of cooperative behavior and live in packs of 3-20 individuals (Iyengar et al. 2005). Depending upon prey availability, they may also hunt alone or in pairs (Cohen et al. 1978; Venkataraman et al. 1995).

Dhole packs exhibit a remarkable degree of co-operation in hunting down prey. However, on rare occasions, hunting by lone individuals or a pair has been observed. Hunting strategies and methods may vary depending on hunting pack size, prey type, and habitat conditions. Dholes are primarily diurnal and crepuscular, but are occasionally active during the night (Mehrdadfar et al. 2003). Johnsingh (1983) reported them as predominantly diurnal in habit, hunting mainly in the mornings and evenings. The camera trapping and reported killing of domesticated animals from Nepal showed their activeness during the day time also. They generally predate the wild animals-- Musk deer (Moschus chrysogaster), Muntjak deer (Munitiacus muntjak), Wild pig (Sus scrofa), Ghoral (Nemorhaedus goral), Blue sheep (Pseudois nayaur), Birds, Rabbits and Rodents. According to the herders of KCA, dholes predate the small livestock (Goat/Sheep) in the same number of their pack size (i.e larger dhole pack target more Goat/Sheep numbers) according to the livestock availability. A pack of 2-8 individuals was sighted by herders in Yamphudin in July and August 2010. A Pack of 11 individuals was visualized by herders in pastureland of Yamphudin, a decade ago (L. Sherpa pers. comm.).

In Nepal, these dogs are regarded as vermin of the jungle due to their livestock killing behavior and heavily persecuted in the past by poisoning and/or shooting. According to the 
history of dholes told by the villagers of KCA, the dholes were retaliated through poisoning around 1995, which led to dramatic decline of the dhole population for a decade.

\section{Study Area:}

$\mathrm{KCA}\left(2,035 \mathrm{~km}^{2}\right)$ is located in the northeast corner of Nepal $\left(27^{0} 36^{\prime} 14^{\prime \prime} \mathrm{N} 87^{0} 56^{\prime} 02^{\prime \prime}\right.$ E), bordering Sankhuwasabha to the west and other VDCs of Taplejung to the south, Sikkim-India, in the east, and the Tibet Autonomous Region- China, in the north (Figure 1).

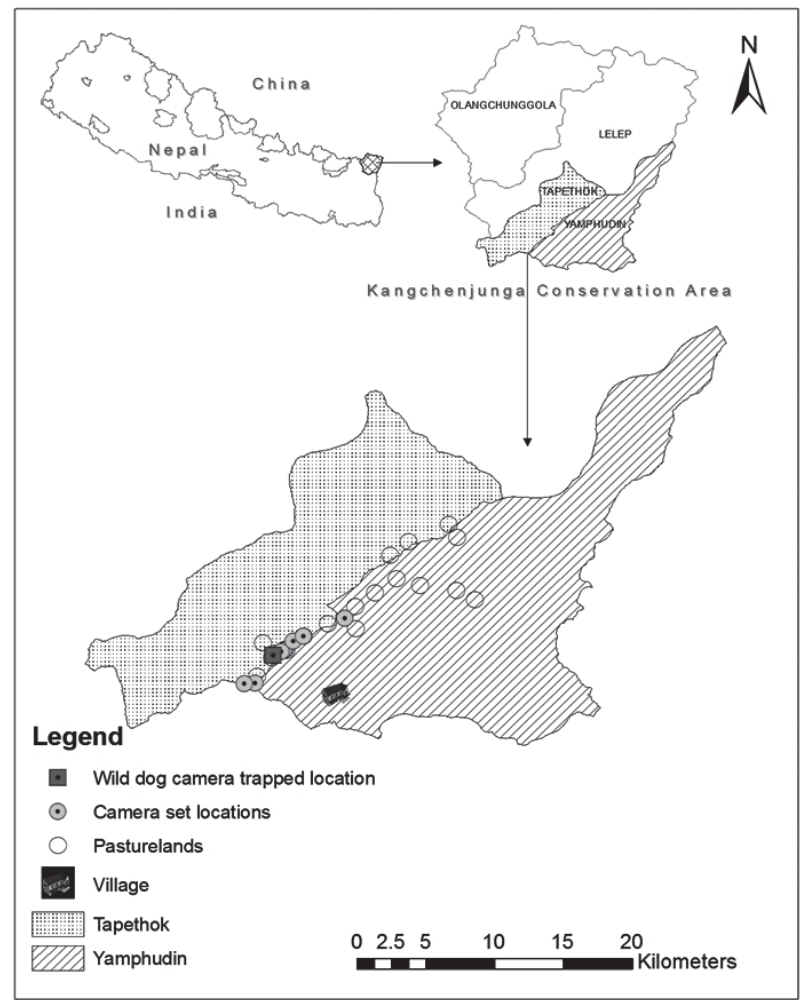

Figure 1: Study area
The Qomolongma National Nature Reserve of China lies to the north and the Kanchenjunga National Park in Sikkim in India to the east.

KCA is Nepal's most isolated and least densely populated protected area. Its elevation ranges from 1,200 meters above sea level to a high of 8,586 meters at the summit of Mount Kangchenjunga, the third-highest peak in the world. With its pristine forests, alpine meadows, and high-altitude wetlands, KCA is home to the endangered snow leopard, the red panda, and the dhole, among other fascinating species. KCA was first declared as a 'Gift to the Earth' in support of the WWF's Living Planet

Campaign and officially conferred Conservation Area status by Government of Nepal (GoN) on 21 July 1997. KCA covers more than 50\% of the Taplejung district encompassing the Walangchung Gola, Lelep, Yamphudin and Tapethok Village Development Committees (VDCs). The government of Nepal handed over the management responsibility of KCA to the local community forming Kangchenjunga Conservation Area-Management Council KCA-MC in 22 September 2006. This study was mainly carried out in Yamphdin VDC. 


\section{Methodology:}

This study focused specifically on camera trapping and human-wildlife conflict in the study area. The fieldwork - which began on August 11, 2010, and ran for a month - employed 10 camera traps for 17 days for 24 hours, surveys and interviews to gather data on the status and distribution of the dhole in the KCA, particularly in Yamphudin, and to provide insight into the animal's impact on the local environment. The cameras were placed in the strategic locations identifying the dhole walking route. The opportunistic locations were recognized by consulting the herders. Cameras were placed with the support of trees, shrubs, wooden stick and stones along the side of human trails and livestock grazing route from Sammewa Daurali to Naya Jhodeni danda. The height of the camera was varied from 2 feet to 5 feet from ground level but the laser light of every camera was focused below the human knee and fixed them with the help of rope to the tree, shrubs and wooden stake. The cameras were not camouflaged and no any bating technique was adopted.

Two group discussions were carried out in Yamphudin ward no. 8 and ward no. 2. Checklist was prepared to direct the group discussion on subject matter. Sighting reports, livestock killed by dholes, dholes' history, and population trend, most probable pasture lands of dhole habitat and perception of local people regarding dhole was collected during these discussions.

The study used camera traps to establish the presence of dholes in the KCA - before the study, evidence of their presence was insufficient. A survey of signs of wild dog covered 106 plots, among them 53 plots contained the dhole sign (scat, pugmarks, and carcasses of dhole prey). For the social information, 53 interviews were conducted. Local people, herders, and members of the KCA management council were asked about their knowledge of dhole distribution, instances of human-wild dog conflict, and the history of dholes in the area.

\section{Result and discussion:}

The study found that, more than a decade ago, prior to the establishment of KCA, dhole populations were relatively high in Yamphudin, and there were occasional attacks on livestock. The local population retaliated against dholes by poisoning or shooting them, which led to a dramatic decline in the species' numbers. The population revived somewhat after the establishment of KCA, and in 2007 communities again began to report sightings and livestock kills by dholes. However, there were no formal studies to confirm that dholes - and not other predators, such as snow leopards - were responsible for the kills. The SLCC Yamphudin sector record shows that most of the depredation was by dholes rather than snow leopard.

Data collected about sightings by local herders, along with reported killings of domesticated animals, indicated that a pack of eight dholes passed through KCA in the Barule area. A pair of dholes was sighted in Lase, six dogs were reported in Sammewa Vedichowk/Daurali, 
and four in Phunchebung. Additionally, three pictures of dholes were photographed on 22 August 2010 with camera traps in Sammewa Daurali at an elevation of 3759 m.

Dholes are widely distributed throughout KCA and are found at elevations between 1,900 and 4,350 meters. They are opportunistic hunters, preying on whatever animals they encounter, such as mountain sheep, deer, rodents and rabbits. Dholes generally prefer to hunt during dawn or dusk in the sites of minimum human disturbance. Rarely will they seek out domesticated animals as prey but due to increasing interaction with domesticated animals in pasture lands and being easy to prey than wild animals, the dholes attack on domesticated animals had increased.

Herders in KCA rely on their livestock to feed their families and sell at market. The loss of just one animal can ruin a family; therefore, when wild animals kill a cow, goat or sheep the herders often retaliate by shooting the attackers or baiting them with poisoned carcasses. In Yamphudin, snow leopards were formerly the main threat but since October 2007, however, 14 Yak/Cows (87.5\%) in the area had been killed by dholes.

In 2006, the Kangchenjunga Conservation Area Project (KCAP) initiated a livestock insurance scheme with the SLCC to reduce human-snow leopard conflict. The SLCC has already provided NRs. 35,000 in relief funds to dhole affected herders, to discourage them from killing the predators that attacked their livestock. The SLCC provides NRs. 2,500 per cow killed by a snow leopard or dhole (there is no insurance for goats and sheep).

Habitat fragmentation due to slash/burn practice, forest products collection, and humandhole conflict are current threats to dholes in KCA. The local people have negative attitudes towards dholes because of their livestock killing behavior. Sometimes, the herders secretly use poison against dholes to reduce the loss of their livestock in the pasturelands, which is causing an increased threat to dhole survival in KCA. Additionally, with the establishment of KCA, herbivore populations have increased and there has been an increase in crop raiding by muntjak deer, Himalayan porcupine and macaque (B. Phembo, K. Limbu, G. Sherpa, A. Rai pers. comm.). Therefore, the dholes would have important role to regulate the herbivore population to minimize the loss of crops.

\section{Conclusion and Recommendation:}

This study confirmed that the presence of dholes in KCA. They are widely distributed in pasturelands and conservation community forests of Lelep, Tapethok and Yamphudin VDCs. They are also distributed in adjacent forest and pasturelands of KCA and killing livestock. The livestock depredation in Yamphudin is mostly by the dholes. On the basis of sighting reports and reported killings 15/20 individuals of dholes were estimated in Yamphudin (312.96 sq. km). Dholes generally preferred the areas of minimum human disturbance, sufficiently available prey species, rocky areas with some escaping caves, water sources and open lands with adjoining forest and shrubby areas. They follow the ridge line of the mountains along human and grazing trails. Occasional forest fire, loss of 
prey, human persecutions, poisoning and habitat fragmentation due to livestock grazing and forest product collection are major challenges for dholes to survive in KCA.

To support conservation of dholes in KCA, local community awareness needs to be raised, and the relief fund should be increased to compensate livestock owners at a satisfactory level. Creating income alternatives to herding - such as production of high-yield non-timber forest products - would be another positive step toward the conservation of dholes in KCA. In the meantime, the relief fund provides assistance to herders and helps increase awareness about dholes in the area. This study has provided the baseline information drawing attention of KCA management council and concern government authority to take action for dhole conservation in KCA.

\section{Reference:}

Cohen, J.A., Fox,M.W., Johnsingh, A.J.T. and Barnett, B.D. 1978. Food habits of the Dhole in South India. The journal of the wildlife management. 42: 933-936.

ICIMOD.2010. Climate Change Impact and Vulnerability in the Eastern Himalayas - Technical Report 2/ ICIMOD

IUCN.2010. IUCN Red List of Threatened Species. Version 2010.4. <www.iucnredlist.org>. Downloaded on 26 December 2010.

Iyengar, A., Babu V.N., Hedges,S., Venkataraman, A.B., Maclean, N. and Morin, P.A.2005. Phylogeography, genetic structure, and diversity in the dhole (Cuon alpinus). Molecular Ecology. 14, 2281-2297.

Johnsingh, A. J. T. 1983. Large Mammalian Prey-Predators in Badipur. Journal of Bombay Natural History Society. 80 (1): 1-57

Johnsingh, A. J. T. 1985. Distribution and status of dhole Cuon alpinus Pallas, 1811 in South Asia. Mammalia 49(2): 203-208.

Mehrdadfar, F., Chuven,J., Casavant K. and Barnes.K. 2003. Husbandry of Dholes at San Diego Wild Animal Park. International Zoo News. 50 (8): 462-466.

Venkataraman, A. 1998. Male-biased adult sex ratios and their significance for cooperative breeding in dhole, Cuon alpinus packs. Ethology, 104, 671-684.

Venkataraman, A. B., Arumugam,R. and Sukumar, R. 1995. The foraging ecology of dholes (Cuonalpinus) in Mudumalai sanctuary, southern India. Journal of Zoology. 237: 543-561

Wikipedia. 2011. Social and territorial behavior. http://en.wikipedia.org/wiki/Dhole Downloaded on 13 January 2011 